\title{
A comparison of teaching methods that provide patient orientation to inpatient unit procedures
}

\author{
Kimberly Adler ${ }^{1}$, Crystal McKeever ${ }^{1}$, Aubrey Dyer ${ }^{1}$, Marylee Donaldson ${ }^{1}$, Peggy Ward-Smith ${ }^{* 2}$ \\ ${ }^{1}$ North Kansas City Hospital, United States \\ ${ }^{2}$ School of Nursing and Health Studies, University of Missouri - Kansas City, United States
}

Received: October 8, 2018

DOI: $10.5430 /$ cns.v7n2p48

\author{
Accepted: February 13, $2019 \quad$ Online Published: February 24, 2019 \\ URL: https://doi.org/10.5430/cns.v7n2p48
}

\begin{abstract}
The descriptive longitudinal feasibility study compared two teaching methods focused on inpatient unit orientation. Once admitted, 20 patients were randomly assigned to one of two methods (written or video) that provided unit orientation information. Survey data, which assessed retention of the information and satisfaction with the instructional method, were collected 24 hours later. Descriptive analyses of these data determined that patients who received unit orientation information by video achieved a slightly higher knowledge score, but a slightly lower satisfaction with instruction score. These data demonstrate that the teaching modality has an effect on patient knowledge retention and satisfaction with care. Correlating the descriptive patient demographic and admitting diagnosis data to the study variables revealed that when the admitting diagnosis was alcohol-related there was a negative influence on knowledge retention, which was a surprising result. Coordinating the mode of instruction to patient data, and/or allowing the patient to choose their instructional method may enhance the inpatient experience.
\end{abstract}

Key Words: Unit orientation, Video instruction, Written instruction, Patient knowledge and satisfaction

\section{INTRODUCTION}

The decision to admit anyone to an acute care facility is often an urgent, yet necessary activity to provide healthcare. Orientation to the inpatient hospital unit, hospital routines, and care expectations, are meant to decrease anxiety and provide realistic expectations. Qualitative research by Dyrstad, Laugaland, and Storm ${ }^{[1]}$ concluded that variations exist in how healthcare professionals provide information. Knowledge of the cognitive status of the patient, specifically if they are older, should guide the provision and the necessity of reinforcing information. Data from this study describes patients who were satisfied with the information provided, but admitted that they could not remember much of it. Rose, Bowman, and Kresevic ${ }^{[2]}$ explored the perceptions of nurses and caregivers related to the patient's health condition upon admission. While not directly related to the aim of this study, the results of this study document little congruence between nurses and caregivers with respect to the patient's health condition, which may impact the ability to understand orientation instructions. While unit orientation is provided as a part of any inpatient admission, there is a paucity of data exploring the potential for non-verbal and self-directed methods of instruction. The aim of this pilot study was to determine the effectiveness of two alternative methods of instruction, videotaped and an instructional pamphlet, as teaching methods. These instructional methods have the potential of providing knowledge specific to unit routines while unencumbering the nursing staff with this activity. Ul-

\footnotetext{
*Correspondence: Peggy Ward-Smith; Email: wardsmithp@umkc.edu; Address: School of Nursing and Health Studies, University of Missouri -
} Kansas City, United States. 
timately, the goal was to determine if alternative methods of instruction were appropriate, which would provide the nursing staff with additional time to provide direct care.

\subsection{Background}

Patient centered care is one of the Institute of Medicine's ${ }^{[3]}$ six objectives toward improving healthcare in the 21 st century. Compassionate, empathetic and responsive to the needs, values and expressed preferences of each patient are variables included in the IOM's perception of patient care. Davis and colleagues ${ }^{[4]}$ describe patient-centered care as "providing care that the patient needs in the manner the patient desires at the time the patient desires (p. 953)." Correlating patient centered care to improved patient outcomes has been identified by Stewart and associates ${ }^{[5]}$ as well as Bechel, Meyers, and Smith. ${ }^{[6]}$ Research results from Dyrstad, Laugaland, and Storm ${ }^{[1]}$ identified patient preference for participatory decision-making during the admission process some wanted to be involved, and some did not. A review of the literature failed to identify data that compared patient knowledge and satisfaction specifically toward unit orientation. Based in the premise that this activity provides a framework to decrease patient anxiety and set care expectations, unit orientation is a pivotal time for impacting the admission experience.

Once admitted to an inpatient unit, nurses provide information specific to unit procedures. This information is different than hospital orientation information, which may be provided prior to a scheduled admission, and focuses on the services of the facility, navigating the premises, and availability of support services. Inpatient orientation is specific to the unit and describes policies which may include visitor restrictions, scheduling of treatments and meals, laboratory and physician rounding times, and resources. The purpose of these orientation activities are aimed at decreasing the uncertainty and anxiety associated with an inpatient hospital stay. The aim of this feasibility study was to determine if understanding and retention of information were affected by the method of unit specific instruction.

Orientation to the unit is different from information provided pre-admission specific to the planned procedure, usual hospital stay, and general routines. Pre-hospital information may be provided by the physician office, the pre-procedure testing center, or the hospital admission department. Pre-admission information is general and meant to prepare the patient and his/her family members about hospital routines, in general. Unit specific information is provided upon admission to the unit, is specific to the plan of care, and describes goals or milestones that need to be met prior to dismissal. At the study site, this information is typically provided verbally, at the time of admission. Anecdotal conversations among nursing staff led to the realization that this approach may not provide an optimal learning environment and other methods needs to be considered. Admission activities are multiple, complex, and completed in a stressful, hurried atmosphere. Thus, the decision was made to compare comprehension of the information when provided through either a videotaped or written format.

\subsection{Purpose}

The purpose of this descriptive, comparative study was to determine if retention of unit specific policies was impacted by the method of instruction. Comparison data were obtained after one of two interventions were provided: videotaped or written unit orientation instruction. The significance of this study will be realized in its ability to provide patient information in the preferred manner for the newly admitted patient, thus enhancing the inpatient experience.

\section{METHOD}

\subsection{Study setting}

Data for this study were obtained from patients admitted to a 38-bed medical unit that provides acute care to patients with renal health conditions and/or those requiring telemetry monitoring. This unit is part of a 451-bed not-for-profit healthcare setting, located in a Midwestern Urban city.

\subsection{The interventions}

A unit specific written information pamphlet was developed for this study. Included in this pamphlet was detailed information regarding meal times, visiting hours, when routine laboratory tests occurred, the scheduling of tests that required going off-unit, vital sign monitoring routines, typical physician rounding times, and in-hospital resources available (chaplain, volunteers, gift shop). The orientation videotape, made specifically for this study, contained the same information provided on the pamphlet, and was accessed via a specific channel on the hospital-provided television set. The pamphlet was developed first, to ensure that the videotape would contain the same information. Both informational interventions were developed by the nurses who provide direct care on the study unit and were individually reviewed by these individuals prior to the initiation of and study activity.

\subsection{Sampling and recruitment}

A power analysis, determined a priori, calculated that a sample size of 20 would be required to determine a large effect size (0.50), with a 0.05 error probability, and a .80 effect size $^{[7]}$ when descriptive statistics were the only planned statistical analyses. Approval for this research was provided by the Institutional Research Council (IRC) as an exempt 
study. As a pilot study, a large effect size is appropriate when determining if differences are present. ${ }^{[8]}$ Using a randomized control trial study design, 20 consecutive patients who met study inclusion criteria were invited to participate in the study. As an exempt education study, consent was not required. Each study participant received orientation information in either written or videotaped format, within the initial 24 hours of their admission. The study inclusion criteria prevented individuals who were not medically stable, unable to speak or comprehend English, whose admitting diagnoses included cognitive impairment, or where the plan of care included a medical intervention within the initial two hours of admission from participating. Randomization, determined by the admitting nurse, was done by flipping a coin; heads indicated that orientation was to be provided using the videotaped format and tails indicated that the written format was to be utilized. The study interventions were an educational orientation, using either the videotaped or written format, and provided once the patient was settled in the hospital bed and the initial set of vital signs were obtained. Each patient received their unit orientation information individually, within their inpatient hospital room. Family members, if present upon admission, were allowed to participate in the orientation informational session.

\subsection{Data collection and analyses}

Demographic information was obtained from the medical record by researchers whose job responsibilities provided access to this information. This provided compliance with present patient confidentiality regulations. Patient knowledge was assessed 24 hours later, or during the second inpatient day, using responses to 10 multiple choice items, which reflected content provided within the information. Knowledge items focused on unit policies (visiting hours, going off the unit) and procedures (meal, blood draw, and medication times) as well as general information (physician rounding schedule), how to contact the nurse, and in-hospital resources. Each survey item correlated to data provided in either educational intervention. Content validity, which is the ability for the item to adequately measure the concept under investigation, and face validity, which is the validation of the instrument measure what the name suggests it measures, ${ }^{[8]}$ were assessed by the research team and determined to be present. Satisfaction with the orientation educational process was described based on 10-point $(0=$ not at all to $10=$ a great deal) Likert responses to 12 items. Once completed, the patient placed their survey in a sealed envelope and handed to one of the research team members. The sealed envelope was forwarded to the study coordinator who maintained all study files in a locked cabinet. Once all study data were collected, responses were hand entered into a study-specific SPSS file and analyzed using descriptive techniques.

\section{RESUlts}

Participant gender was slightly different; the written study population was composed of 6 females and 4 males, while the videotaped study group had 2 females and 8 males. This difference occurred by chance. The age range for each study group also varied slightly; ages the written study group ranged from 44 to 84 years, with a mean of 66 years while ages of the videotaped study group ranged from 35 to 76, with a mean of 56.67 years $(p=.051)$. The primary reason for hospital admission was a medical condition; respiratory or renal in nature, and similar between the two groups. Survey response scores were calculated based on the correct response for the informational items and ranked for the evaluative items. This information is summarized in Table 1.

Table 1. Study population demographic data

\begin{tabular}{|c|c|c|}
\hline Study Group & Videotaped Information & Written Handout Information \\
\hline Gender & Male $=8 ;$ Female $=2$ & Male $=4 ;$ Female $=6$ \\
\hline Age & Range 35-76; mean = $56.67(S D=15.57)$ & Range 44-84; mean $=66(\mathrm{SD}=11.98)$ \\
\hline Reason for Admission & $\begin{array}{l}\text { - } \text { Respiratory medical problem }=2 \\
\text { - } \text { Cardiovascular medical problem = } 1 \\
\text { - } \text { Kidney medical problem = } 1 \\
\text { - } \text { Infection = } 1 \\
\text { - Other = } 5 \text { (cellulites [3], nausea [1], cirrhosis [1]) }\end{array}$ & $\begin{array}{l}\text { - Respiratory medical problem }=3 \\
\text { - Kidney medical problem }=4 \\
\text { - Other }=4 \text { (cellulites [2], abdominal pain } \\
\text { [1], alcohol intoxication)[1] }\end{array}$ \\
\hline
\end{tabular}

Responses to the informational items varied between the groups. Summed correct responses for the participants who received their information in the videotaped format ranged from 50 to 100 , with a mean of $83(\mathrm{SD}=15.67)$ while participants who received their orientation using the written handout format ranged from 30 to 70, with a mean of 72 $(\mathrm{SD}=27.80)$. While there were greater variance among participants in the written format study group, there was no statistical significance between the two groups $(p=.602)$. The potential range for satisfaction scores was 0 to 120 . Sat- 
isfaction scores were also summed; scores for participants in the videotape group ranged from 26 to 120 , with a mean of 87.7 ( $\mathrm{SD}=27.56)$. Satisfaction cores for the participants in the written format study group ranged from 41 to 113 , with a mean of $90(\mathrm{SD}=28.34)$. While the summed scores varied, no statistical significance was identified between the two groups $(p=.046)$. These data are displayed in Table 2 .

Table 2. Survey summed scores by study group

\begin{tabular}{lll}
\hline Study Group & Videotaped Information & Written Handout Information \\
\hline Total quiz scores & Range 50-110; mean = 83 (SD = 15.67) & Range 30-100; mean = 72 (SD = 27.80) \\
Total information scores & Range 26-121; mean = 87.7 (SD = 27.56) & Range 41-113; mean = 90 (SD = 28.34) \\
\hline
\end{tabular}

Table 3. Responses to each survey item, by study group

\begin{tabular}{|c|c|c|}
\hline Item & Videotaped Information & Written Handout Information \\
\hline $\begin{array}{l}\text { How much information did you need from your nurses about } \\
\text { what care to expect for your first few days in the hospital? }\end{array}$ & $\begin{array}{l}\text { Range 0-8; Mean } 6.50 \\
(\mathrm{SD}=3.30)\end{array}$ & $\begin{array}{l}\text { Range } 0-10 ; \text { Mean }=5.56 \\
(\mathrm{SD}=3.64)\end{array}$ \\
\hline $\begin{array}{l}\text { How much information did you receive from your nurses about } \\
\text { what care to expect for your first few days in the hospital? }\end{array}$ & $\begin{array}{l}\text { Range 0-9; Mean } 6.90 \\
(\mathrm{SD}=3.24)\end{array}$ & $\begin{array}{l}\text { Range 4-10; Mean = } 7.33 \\
(\mathrm{SD}=2.39)\end{array}$ \\
\hline $\begin{array}{l}\text { How much information did you need from your nurses about } \\
\text { unit routine during your first few days in the hospital? }\end{array}$ & $\begin{array}{l}\text { Range 0-9; Mean } 5.70 \\
(\mathrm{SD}=2.58)\end{array}$ & $\begin{array}{l}\text { Range 3-10; Mean } 6.22 \\
(\mathrm{SD}=3.51)\end{array}$ \\
\hline $\begin{array}{l}\text { How much information did you receive from your nurses about } \\
\text { unit routines during your first few days in the hospital? }\end{array}$ & $\begin{array}{l}\text { Range 1-9; } \text { Mean }=6.60 \\
(\mathrm{SD}=2.95)\end{array}$ & $\begin{array}{l}\text { Range } 0-10 ; \text { Mean }=6.11 \\
(\mathrm{SD}=3.51)\end{array}$ \\
\hline $\begin{array}{l}\text { How much information did your family members need from } \\
\text { your nurses about what care to expect for your first few days in } \\
\text { the hospital? }\end{array}$ & $\begin{array}{l}\text { Range } 2-10 \text { [5 NA responses]; } \\
\text { Mean }=8.30 \\
(\mathrm{SD}=4.47)\end{array}$ & $\begin{array}{l}\text { Range } 0-10 \text { [2 NA responses }] \\
\text { Mean }=6.56 \\
(\mathrm{SD}=4.24)\end{array}$ \\
\hline $\begin{array}{l}\text { How much information did your family members receive from } \\
\text { your nurses about what care to expect for your first few days in } \\
\text { the hospital? }\end{array}$ & $\begin{array}{l}\text { Range } 1-10 \text { [6 NA responses]; } \\
\text { Mean }=9 / 20 \\
(\mathrm{SD}=3.45)\end{array}$ & $\begin{array}{l}\text { Range } 1-10 \text { [2 NA responses]; } \\
\text { Mean }=8.44 \\
(\mathrm{SD}=3.35)\end{array}$ \\
\hline $\begin{array}{l}\text { How much information provided by your nurses answered your } \\
\text { specific concerns and questions about the unit routines? }\end{array}$ & $\begin{array}{l}\text { Range } 0-10[1 \text { NA response }] \\
\text { Mean }=7.00(\mathrm{SD}=3.33)\end{array}$ & $\begin{array}{l}\text { Range 5-10; } \text { Mean }=8.22 \\
(\mathrm{SD}=2.22)\end{array}$ \\
\hline $\begin{array}{l}\text { Was the information your nurses provided about unit routines } \\
\text { while in the hospital presented in a way you could understand? }\end{array}$ & $\begin{array}{l}\text { Range } 0-10 ; \text { Mean }=7.70 \\
(\mathrm{SD}=3.59)\end{array}$ & $\begin{array}{l}\text { Range } 5-10 ; \text { Mean }=8.22 \\
(\mathrm{SD}=2.22)\end{array}$ \\
\hline $\begin{array}{l}\text { Did your nurses check to make sure you understood the } \\
\text { information and instructions? }\end{array}$ & $\begin{array}{l}\text { Range 1-10; } \text { Mean }=7.00 \\
(\mathrm{SD}=3.59)\end{array}$ & $\begin{array}{l}\text { Range 0-10; } \text { Mean }=7.00 \\
(\mathrm{SD}=3.64)\end{array}$ \\
\hline $\begin{array}{l}\text { Did you receive consistent (the same) information from your } \\
\text { nurses and other health care providers about unit routines? }\end{array}$ & $\begin{array}{l}\text { Range } 0-10 ; \text { Mean } 7.40 \\
(\mathrm{SD}=3.65)\end{array}$ & $\begin{array}{l}\text { Range 5-10; Mean = } 8.13 \\
(\mathrm{SD}=2.35)\end{array}$ \\
\hline $\begin{array}{l}\text { Was the information about unit routines given to you at times } \\
\text { that were good for you? }\end{array}$ & $\begin{array}{l}\text { Range 0-10; Mean }=7.10 \\
(\mathrm{SD}=3.47)\end{array}$ & $\begin{array}{l}\text { Range 5-10; Mean } 8.11 \\
(\mathrm{SD}=2.31)\end{array}$ \\
\hline $\begin{array}{l}\text { Was the information you received from your nurses provided at } \\
\text { times when your family member(s) or others could listen? }\end{array}$ & $\begin{array}{l}\text { Range 3-10 [4 NA responses]; } \\
\text { Mean }=8.30(\mathrm{SD}=3.16)\end{array}$ & $\begin{array}{l}\text { Range 5-10 [2 NA responses]; } \\
\text { Mean }=9.22(\mathrm{SD}=2.16)\end{array}$ \\
\hline Information summary & $\begin{array}{l}\text { Range 26-121; Mean = } 87.70 \\
(\mathrm{SD}=27.56)\end{array}$ & $\begin{array}{l}\text { Range 41-113; Mean }=90.00 \\
(\mathrm{SD}=28.34)\end{array}$ \\
\hline
\end{tabular}

Despite the lack of statistical differences in knowledge or satisfaction with the method of orientation, the variation in responses describe clinical significance. One study participant in the videotaped study group achieved a perfect score while three study participants in the written format study population achieved a perfect score on the knowledge assessment survey. Visiting hours were understood by all participants in the videotaped study group, while this was misunderstood by one participant in the written study popu- lation. The inability to leave the unit if being monitored was known by all participants in the videotaped study population and misunderstood by 3 of the 10 participants in the written study population. Patients admitted with alcohol related co-morbidities (cirrhosis, intoxication) scored the lowest on the knowledge assessment, and reported the greatest dissatisfaction with the information provided, regardless of the orientation method used. In addition to the educational intervention, each nurse provided a follow-up contact, within the 
initial 24 hours and prior to data collection, to assure that the information was understood, and to answer any questions. This was done to ensure that the information was understood. In an effort to determine the satisfaction with each intervention, the satisfaction items focused on the need, and content, of supplemental instruction. Specific response differences, by orientation methodology, is available in Table 3 .

\section{DiscuSSION OF THE FINDINGS}

The results of this study begin to explore the impact different teaching modalities have on unit orientation knowledge and satisfaction with care among patients admitted to an acute care health facility. Demonstrating that there are differences in knowledge retention based on the format used to provide orientation provides a framework for additional research.

While providing orientation information to patients upon admission to an acute care health facility is routinely performed, the methodology of this information appears to impact the knowledge retention and satisfaction with care among patients. In 2001, the $\mathrm{IOM}^{[3]}$ outlined objectives aimed at improving care. Providing unit orientation information, in a format desired by patients, seems to align with these objectives. The ability to provide unit orientation, verbally, to all patients admitted to an inpatient acute care facility in a timely manner is challenging. While patients need to understand unit-specific policies and procedures, providing this information during the myriad of activities associated with hospital admission may not provide the best educational format. Using alternative means, such as a videotape or an educational pamphlet, aligns with providing patient-centered care as described by Davis and colleagues. ${ }^{[4]}$ Allowing patients to select their preferred method of unit orientation, using patient demographic information, or the admitting diagnosis to guide the educational method supports the research results of Stewart and associates ${ }^{[5]}$ and has the potential to improve patient outcomes. While these the results of this study are limited, they do demonstrate that other unit orientation methods, besides verbal and when reinforced with follow-up, have value. Thus, considering alternative means of unit orientation should be considered. These alternate means have the ability to reduce the number of activities necessary during a stressful time while increasing the ability for the nurse to focus on care concerns.

\section{Limitations}

There are several limitations associated with this study. One limitation is the small number of study participants. A larger study population, and data from diverse units, would be warranted prior to implementing any practice changes. Yet, these pilot data do indicate that variability in the method of providing unit orientation appears to have value. Another limitation was the use of one data collection site, yet this provided specificity of the results, providing credibility for further research using larger sample sizes and various inpatient unit settings to determine generalizability. The survey used for data collection was specific to the unit, and to the policies / procedures for that unit. Thus, while the survey is reflective of this setting, generalizability to other acute care units is not practical. This limitation also inhibits the adequately determine the reliability of the survey, or to provide more than content and face validity.

\section{Conclusion}

This research was meant to be a feasibility study, specifically to determine if there was a preferred orientation method and to describe patient satisfaction with either method of orientation. These data reflect that neither method is perfect, and follow-up reminders and repetition is necessary. ${ }^{[1,2]}$ The implication for nursing, based on these results, is that unit orientation information may need to be repeated, or reinforced. Further research is aimed at identifying the patient, either by age group or admitting diagnosis that would benefit from one specific methodology. An unanticipated result was the identification of the impact an alcohol-related co-morbidity has on understanding information provided upon admission specific to unit routine, and the dissatisfaction with information provided. These individuals represent a vulnerable population; one that may require specific information that is repeated at salient points during their inpatient hospital stay.

\section{ACKNOWLEDGEMENTS}

The authors would like to acknowledge the following people for their contribution and support of this research: Vivian Porter, MSN, RN, ANP-BC, PCCN; Marianne Chulay, PhD, RN.

\section{Conflicts of InTEREST Disclosure}

The authors declare they have no conflicts of interest.

\section{REFERENCES}

[1] Dyrstad DN, Laugaland KA, Storm M. An observational study of older patients' participation in hospital admission and discharge - exploring patient and next of kin perspectives. Journal of Clinical Nursing. 2015; 24(11-12): 1693-1706. https://doi .org/10.111 $1 /$ jocn. 12773 
[2] Rose JH, Bowman KF, Kresevic D. Nurse versus family caregiver perspectives in hospitalized older patients: An exploratory study of agreement at admission and discharge. Health Communication. 2000; 12(1): 63-80. https://doi.org/10.1207/S15327027HC1201_ 04

[3] Institute of Medicine. Crossing the Quality Chasm: A New Health System for the 21st Century. Washington, DC: National Academy Press; 2001.

[4] Davis K, Schoenbaum SC, Audet AM. A 2020 vision of patientcentered primary care. Journal of General Internal Medicine. 2005; 20: 953-957. https://doi.org/10.1111/j.1525-1497.2005 $.0178 . \mathrm{x}$
[5] Stewart M, Brown JB, Donner A, et al. The impact of patient-centered care on outcomes. Journal of Family Practice. 2000; 49: 796-804.

[6] Bechel DL, Myers WA, Smith DG. Does patient-centered care pay off? The Joint Commission Journal on Quality Improvement. 2000; 26: 400-409. https://doi.org/10.1016/S1070-3241(00) 2 6033-1

[7] Faul F, Erdfelder E, Buchner A, et al. Statistical power analyses using $\mathrm{G}^{*}$ Power 3.1: Tests for correlation and regression analyses. Behavior Research Methods. 2009; 41: 1149-1160. https : //doi.org/10.3758/BRM.41.4.1149

[8] Polit DE, Beck CT. Nursing research: Generating and assessing evidence for nursing practice. Philadelphia: Wolters Kluwer; 2017. 